\title{
Biostimulant properties of cyanobacterial hydrolysate related to polyamines
}

\author{
Átila Francisco Mógor ${ }^{1}$ Vince Ördög ${ }^{2,3}$ • Guiseppina Pace Pereira Lima ${ }^{4}$. \\ Zoltán Molnár $^{2} \cdot$ Gilda Mógor $^{1}$
}

Received: 21 February 2017 / Revised and accepted: 27 July 2017 / Published online: 7 August 2017

(C) Springer Science+Business Media B.V. 2017

\begin{abstract}
Developing new and natural sources of plant growth promotors is essential to ensure the safe and sustainable production of vegetables for human consumption. In recent years, the potential of microalgae as plant biostimulants has been investigated. Arthrospira platensis (Spirulina platensis) biomass is a recognized protein source and its enzymatic hydrolysis contains molecules such as polyamines with potential to promote plant growth. Therefore, the aim of the present study was to investigate the biostimulant properties of hydrolyzed biomass of A. platensis. Bioassays were performed to determine auxin-like and cytokinin-like bioactivity of the hydrolysates. In addition, its effect on lettuce seedling growth was investigated and an organic system field trail performed where yield and free polyamine levels in leaves quantified. The hydrolysates had a cytokinin-like effect in the bioassay. Foliar applications promoted the growth of lettuce seedlings with the 4-h reaction hydrolysate (Sph4) being the most effective at promoting growth and increasing the spermine content by $64 \%$ in the lettuce leaves. The polyamine concentration was also compared in nonhydrolyzed A. platensis and Sph4. Hydrolysis resulted in a $34 \%$ increase in spermine content. It was concluded that Sph4 is a natural plant growth promoter that can be used as a raw material for biostimulants, and spermine could be an active compound and a metabolic indicator of Sph4 bioactivity.
\end{abstract}

Átila Francisco Mógor

afmogor@gmail.com

1 Universidade Federal do Paraná, Rua dos Funcionários, 1540, Curitiba 80035-050, Brazil

2 Széchenyi István University, Győr, Mosonmagyaróvár, Hungary

3 University of KwaZulu Natal Pietermaritzburg, Durban, South Africa

4 Universidade Estadual Paulista - UNESP, Botucatu, Brazil
Keywords Cyanobacteria $\cdot$ Arthrospira platensis $\cdot$ Lactuca sativa $\cdot$ Biostimulant $\cdot$ Organic production

\section{Introduction}

One of the greatest challenges facing humanity is to balance technological development with environmental conservation. The growing demand for food puts agriculture at the center of this dilemma, especially related to environmental costs of high synthetic agrochemical inputs. In addition, the risk of agrochemical contamination is a concern for consumers, especially with regard to fresh vegetable consumption. Alternative technologies such as the use of natural products with plant growthpromoting effects need to be prioritized as a way to increase productivity in sustainable agricultural systems. Organic vegetable production addresses these environmental issues.

Macroalgae are a well-known source of natural plantpromoting compounds (Arioli et al. 2015). In general, the effect of macroalgae was related to their content of plant hormones (i.e., cytokinins and auxin). However, recent studies suggest that the growth promotion effect of Ascophyllum nodosum, a widely reported macroalga used in agriculture, is not related to the hormone content of the liquid extract but to the capacity of the extract to stimulate endogenous hormone synthesis in the treated plants (Wally et al. 2013). Some bioactive compounds such as polysaccharides (Stadnik and Freitas 2014) and polyamines (Papenfus et al. 2012) identified in the extracts have plant signaling abilities.

The major forms of polyamines (PAs) are putrescine (Put), spermine $(S p m)$, and spermidine $(S p d)$. They are aliphatic amines that are present in every plant cell with their levels changing with certain developmental transitions (Vera-Sirera et al. 2010). Polyamines participate in many metabolic processes such as cell proliferation and differentiation and 
modulate plant growth (Srivastava et al. 2013), with Spm and $S p d$ associated with plant ontogeny and growth promotion and Put with plant senescence (Kusano et al. 2008; Xie et al. 2014).

In recent years, the biotechnological potential of microalgae has aroused interest due to the identification of various substances synthesized by these organisms (Singh et al. 2016), including polyamines (Hosoya et al. 2005; Incharoensakdi et al. 2010). The use of microalgae biomass as biofertilizers or biostimulants has been the subject of recent studies. For example, Acutodesmus dimorphus cellular extract and dry biomass were able to trigger faster germination and enhance plant growth and floral emission on tomato (Garcia-Gonzalez and Sommerfeld 2016; addition of Chlorella vulgaris biomass to the soil improved lettuce seedlings growth (Faheed and Abd-El Fattah 2008; cyanobacteria species elicited positive effects on seed germination and plant growth parameters in wheat and pea, respectively (Hussain and Hasnain 2011; Osman et al. 2010); and Spirulina sp. biomass had a positive effect as a biofertilizer (Aly et al. 2008; Yee et al. 2012).

The cyanobacterium Arthrospira platensis (Spirulina platensis) has a protein-rich biomass with values of approximately $60 \%$ protein. This biomass can be used to obtain protein hydrolysates with valuable biocompounds including Lamino acids (Zhang and Zhang 2013; Lisboa et al. 2016) such as L-arginine and L-ornithine. The decarboxylation of these amino acids is part of the biosynthesis of polyamines (Lima et al. 2008). The presence of PAs in cyanobacteria, allied to the potential improvement on release of bioactive compounds by hydrolysis (Kim et al. 2014, Zhang and Zhang 2013), suggests that A. platensis hydrolysate is capable of promoting plant growth. Thus, the aim of this work was to evaluate the plant growth-promoting properties of A. platensis hydrolysates. Considering the absence of previous reports on the use of A. platensis hydrolysate, a step-by-step approach was adopted (Povero et al. 2016). Bioassays were initially used to determine auxin-like and/or cytokinin-like bioactivity in the hydrolysate. Its effect on the growth of lettuce (Lactuca sativa $\mathrm{L}$.) seedlings was quantified and a field trial under an organic system was conducted where lettuce yield was measured and free polyamines in lettuce leaves determined. In addition, the A. platensis biomass before and after hydrolysis was analyzed with regard to the polyamine content to establish if PAs are possible active compounds and can be used as biochemical indicators of hydrolysate bioactivity.

\section{Material and methods}

\section{Arthrospira platensis production and biomass hydrolysis}

The cyanobacterium strain was provided by Microalgae Collection "Elizabeth Aidar" at Fluminense Federal University, Niteroi, Rio de Janeiro-Brazil. The autotrophic axenic cultivation of Arthrospira platensis was performed in a semi-continuous cultivation system in a photobioreactor (Reichert et al. 2006) using culture medium described by Zarrouk (1966) at the Plant Science and Crop Protection Department of the Federal University of Paraná, ParanáBrazil.

After 45-day cultivation, the biomass was separated from the culture medium by centrifugation, attaining $0.75 \mathrm{~g} \mathrm{~L}^{-1}$ DW and was lyophilized. A portion was reserved for use as a positive control. Another portion was subjected to enzymatic hydrolysis using protease (EC 3.4.22.2, Merck) according Wang and Zhang (2012) and Zhang and Zhang (2013) with reaction times of 2,4 , and $6 \mathrm{~h}$.

\section{Bioassays}

As a first step to identify possible plant growth promoter properties of A. platensis hydrolysates, bioassays were conducted. The bioassay for cytokinin-like effect was conducted using cucumber cotyledons (Cucumis sativus L.) and their expansion was compared to that obtained with $0.3 \mathrm{mg} \mathrm{L}^{-1}$ kinetin (KIN) (Zhao et al. 1992; Stirk et al. 2002). The bioassay for auxin-like effect was performed with root emission bioassays (Tripepi and George 1991) using mung bean (Vigna radiata L.) and C. sativus (Zhao et al. 1992). Rooting was compared to $0.3 \mathrm{mg} \mathrm{L}^{-1}$ indole-3-acetic acid (IAA). The assays were performed with lyophilized A. platensis biomass at concentration of $2 \mathrm{~g} \mathrm{~L}^{-1}$; hydrolyzed A. platensis biomasses hydrolyzed for 2- (Sph2), 4- (Sph4), and 6-hour reaction (Sph6) at a concentration of $2 \mathrm{~mL} \mathrm{~L}^{-1}$; either $0.3 \mathrm{mg} \mathrm{L}^{-1}$ KIN or IAA and a control with distilled deionized water. The number of roots of $V$. radiata and C. sativus was counted and the fresh weight of $C$. sativus cotyledons was measured. All bioassays were done with four replicates in a completely randomized design in the Plant Physiology Laboratory at the Széchenyi István University, Győr-Mosonmagyaróvár, Hungary.

\section{Lettuce (Lactuca sativa $\mathbf{L}$.) seedlings growth}

The second step was to evaluate the potential of the hydrolysates as a raw material for biostimulants. The experiment was conducted under a protected environment (polyethylene filmcovered nursery) at the organic vegetables production research area of the Federal University of Paraná, Brazil. The lettuce cultivar "Vera" (Sakata Seed Sudamerica) was sown on polystyrene trays with 200 cells filled with a commercial substrate (Bioplant).

Foliar applications of aqueous suspensions containing the following: (I) lyophilized biomass of A. platensis $\left(2 \mathrm{~g} \mathrm{~L}^{-1}\right)$; (II) biomass subjected to hydrolysis for $2 \mathrm{~h}$, (III) $4 \mathrm{~h}$, and (IV) $6 \mathrm{~h}$ applied at $2 \mathrm{~mL} \mathrm{~L}^{-1}$ in aqueous suspension; and (V) the control (deionized water) were performed at 10 and 20 days 
after sowing (DAS). Half trays (100 cells) for each experimental treatment were used, with four replications distributed in a completely randomized design. The foliar sprays were done using a $\mathrm{CO}_{2}$-pressurized sprayer with constant pressure (45 psi) at $50 \mathrm{~mL}$ per replication.

The seedlings were collected at 30 DAS where they had five leaves and healthy root growth. Fifteen seedlings of each replication were randomly selected and the following variables were analyzed: fresh and dry weight of leaves and roots, leaf area, and root volume. The leaf area and root volume, after carefully washing over a sieve to avoid losing root parts, were analyzed using the software WinRhizo (Regent Instruments Inc. 2013, Canada) coupled to a LA1600 3D scanner. To obtain the dry weight, both leaves and roots were placed in paper bags and oven-dried at $65 \pm 5{ }^{\circ} \mathrm{C}$ and forced air circulation. The fresh and dry weight was determined with an analytical balance.

\section{Organically grown lettuce (L. sativa)}

Considering that $\mathrm{Sph} 4$ could be a natural biostimulant source for sustainable agriculture and that the biostimulant effect is not related to nutrient supply to the plants but rather to the bioactivity of a range of molecules (du Jardin 2015), the effect of the hydrolysate was evaluated under high soil fertility that is characteristic of long-term organic soil management. The experiment was conducted at the organic vegetables production research area, where an organic system was implemented 10 years ago, at the Federal University of Paraná, under the geographical coordinates $25^{\circ} 25 \mathrm{~S}$ and $49^{\circ} 06^{\prime} \mathrm{W}$ at an altitude of $920 \mathrm{~m}$. The climate, according to Köppen classification, is temperate type $\mathrm{Cfb}$. Chemical analysis of the $0-15-\mathrm{cm}$ layer of soil in the field indicated the average values: $\mathrm{pH}\left(\mathrm{CaCl}_{2}\right)=5.75 ; \mathrm{pH}=6.0$; $\mathrm{Al}^{3+}=0 ; \mathrm{H}^{+}+\mathrm{Al}^{3+}=5.50 \mathrm{cmol} \mathrm{d} \mathrm{m}{ }^{-3} ;$ $\mathrm{Ca}^{2+}=9.85 \mathrm{cmol} \mathrm{dm}{ }^{-3} ; \mathrm{Mg}^{2+}=9.8 \mathrm{cmol} \mathrm{dm}{ }^{-3}$; $\mathrm{K}^{+}=0.54 \mathrm{cmol} \mathrm{dm}^{-3} ; \mathrm{P}=42.6 \mathrm{mg} \mathrm{dm}{ }^{-3} ; \mathrm{C}=32.5 \mathrm{~g} \mathrm{dm}^{-3}$; soil base saturation $=78.59 ; \mathrm{CEC}=25.54 \mathrm{cmol} \mathrm{dm}^{-3}$. Fifteen days prior to planting, the soil was prepared with the incorporation of $4 \mathrm{tha}^{-1}$ organic compost with the following average values: $\mathrm{C}=30.3 \mathrm{~g} \mathrm{~kg}^{-1} ; \mathrm{N}=30.3 \mathrm{~g} \mathrm{~kg}^{-1} ; \mathrm{P}=8.5 \mathrm{~g} \mathrm{~kg}^{-1}$; $\mathrm{K}=6.6 \mathrm{~g} \mathrm{~kg}^{-1} ; \mathrm{Ca}=8.1 \mathrm{~g} \mathrm{~kg}^{-1} ; \mathrm{Mg}=4.1 \mathrm{~g} \mathrm{~kg}^{-1}$. The soil fertilization was done according to the Brazilian regulation for organic agriculture.

The lettuce seedlings obtained as described above, without application of the experimental treatments, were planted spaced at $0.30 \times 0.30 \mathrm{~m}$, arranged in $1.20 \mathrm{~m}$ wide and $36 \mathrm{~m}$ long planting bed (April 2014). At the seventh day after planting, foliar applications of aqueous suspensions with A. platensis biomass subjected to hydrolysis reaction for $4 \mathrm{~h}(\mathrm{Sph} 4)$ at concentrations of 1.0, 2.0, 4.0, and $8.0 \mathrm{~mL} \mathrm{~L}^{-1}$ and a control (deionized water) were initiated. There were four replications distributed in a completely randomized design in plots with 24 plants. The foliar applications were performed using a $\mathrm{CO}_{2}$-pressurized sprayer with constant pressure (45 psi) and volume of $280 \mathrm{~L} \mathrm{ha}^{-1}$. The treatments were repeated weekly to give a total of six applications that ended at 42 DAP, 1 week before the harvest (June 2014).

The four central plants of each plot were collected for the determination of the number of leaves and whole plant fresh and dry weight as described earlier. Four 25-mm foliar discs were collected after the fresh weight determination and immediately frozen with liquid nitrogen for the analysis of free polyamines in completely expanded young leaves.

\section{Free polyamines determination}

To justify the observed growth promotion property of Sph4, the free PAs content of lettuce was determined to take into account its role in plant development. Free PAs in lyophilized biomass of A. platensis, in biomass subjected to 4-h hydrolysis reaction and in fresh lettuce leaves were determined (three replicates per sample) at the Department of Chemistry and Biochemistry, Biosciences Institute, Universidade Estadual Paulista (UNESP), Botucatu, São Paulo-Brazil, according Flores and Galston (1982) with modifications (Lima et al. 2008) as follows. The material was homogenized for $1 \mathrm{~min}$ in 5\% cold perchloric acid $(v / v)$ (Merck, USA) using a homogenizer. After centrifugation for $20 \mathrm{~min}$ at $4{ }^{\circ} \mathrm{C}$ and $3500 \mathrm{rpm}$, dansyl chloride [Sigma-Aldrich, Brazil 95\%] and saturated sodium carbonate were added to the supernatant. Proline (Sigma, min. 99\%) was added after $1 \mathrm{~h}$ at $60{ }^{\circ} \mathrm{C}$ and the mixture was maintained in the dark for $30 \mathrm{~min}$ at room temperature. Toluene was used for the extraction of the dansylated polyamines and aliquots were applied onto thin-layer chromatography plates [glass plates coated with $60 \mathrm{G}$ silica GelMerck $(20 \times 20 \mathrm{~cm})]$ and were separated in laboratory bowls containing chloroform:triethylamine (Merck) (10:1). Putrescine (Sigma, min. 98\%), spermidine (Sigma, min. 98\%), and spermine (Sigma, min. 95\%) standards were submitted to the same process.

The entire procedure was monitored under ultraviolet light $(254 \mathrm{~nm})$. The polyamines were quantified by comparison against the standards which were also applied onto the plates, by fluorescence emission spectroscopy (excitation at $350 \mathrm{~nm}$ and emission measurement at $495 \mathrm{~nm}$ ) in a video documentation system using Image Master version 2.0 software program (Amersham Pharmacia Biotech, Sweden). The free polyamine was expressed as $\mu \mathrm{g} \mathrm{g}^{-1}$ fresh matter.

\section{Data analysis}

The data were tested for homogeneity of variances by Bartlett's test and then analyzed by ANOVA. When 
significant, the averages were compared by Tukey's test. The statistical software Assistat 7.7 Beta was used.

\section{Results}

\section{Bioassays}

Arthrospira platensis lyophilized biomass (Sp) and its hydrolysates (Sph2, 4, and 6) did not promote root emission in $V$. radiata (Fig. 1a). Related to the time of the hydrolysis reaction, $2 \mathrm{~h}$ (Sph2) had a root number similar to that of the control and with increasing hydrolysis reaction time, and root emission was reduced with $V$. radiata showing no roots at 4 (Sph4) and 6 (Sph6) h reaction. The lyophilized biomass ( $\mathrm{Sp}$ ) increased the root number in the cucumber cotyledon bioassay but the hydrolysates had no effect. However, when compared to KIN, the Sph4 and Sph6 hydrolysates increased the fresh weight of cucumber cotyledons compared to the control and $\mathrm{Sp}$. The bioassays indicated that the hydrolysates with
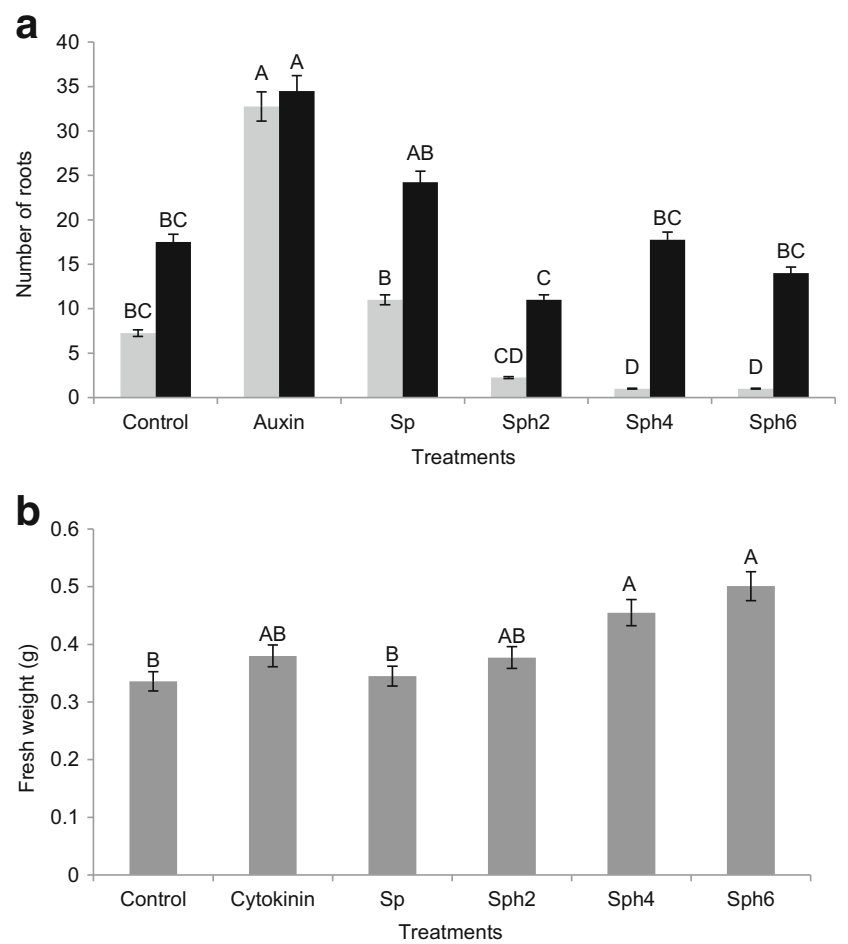

Fig. 1 a Number of roots in Vigna radiata (gray column) and Cucumis sativus cotyledons (black column), using $0.3 \mathrm{mg} \mathrm{L}^{-1}$ indole-3-acetic acid as the auxin standard. b Cucumis sativus cotyledons fresh weight using the $0.3 \mathrm{mg} \mathrm{L}^{-1}$ kinetin as the cytokinin standard. Both compared the suspensions of lyophilized biomass of Arthrospira platensis (Sp) at a concentration of $2 \mathrm{~g} \mathrm{~L}^{-1}$ and $\mathrm{Sp}$ biomasses submitted to hydrolysis for 2 (Sph2), 4 (Sph4), and $6 \mathrm{~h}(\mathrm{Sph} 6)$ at a concentration of $2 \mathrm{~mL} \mathrm{~L}^{-1}$, and to the control. At the same letter in the columns, the values did not differ by Tukey's test $(p<0.05)$. Bars represent standard error increased reaction time ( $\mathrm{Sph} 4$ and $\mathrm{Sph} 6)$ showed lower auxin and higher cytokinin effects (Fig. 1b).

\section{Lettuce (L. sativa) seedlings growth}

At 30 DAS (seedlings growth period at harvest), seedlings treated with Sph4 and Sph6 had increased leaf area (Fig. 2), and increased fresh and dry weight of leaves (Fig. 3a, b) and roots (Fig. 3c, d). On the other hand, Sp $\left(2 \mathrm{~g} \mathrm{~L}^{-1}\right)$ did not promote growth. Similar to the bioassay results (Fig. 1b), longer reaction times of the hydrolysis (Sph4 and Sph6) had a significant effect on promoting growth of lettuce seedlings while the effect of the Sph2 treatment was similar to that of the control. Although there were no statistical differences between the effects of Sph4 and Sph6, Sph4 was selected for the field trial on organically grown lettuce.

\section{Organically grown lettuce}

The effect of six foliar applications of Sph4 at different concentrations on organically grown lettuce resulted in increased fresh weight, leaf number, and dry weight of plants at harvest (Fig. 4), corroborating the growth-promoting effect of the cyanobacterium hydrolysate as found in the C. sativus bioassay and the lettuce seedling experiment. Increases ranging from 30 to $39 \%$ with $1-8 \mathrm{~mL} \mathrm{~L}^{-1} \mathrm{Sph} 4$ of lettuce fresh weight were recorded (Fig. 4a) along with a $15 \%$ increase in leaf number compared to the control (Fig. 4b). As a consequence of the growth promotion, there was almost a doubling of dry weight of lettuce plants treated with Sph4 foliar sprays (Fig. 4c).

\section{Changes of free polyamines in lettuce}

The determination of free polyamines in fresh lettuce leaves revealed no significant differences for $P u t$ and $S p d$ with values

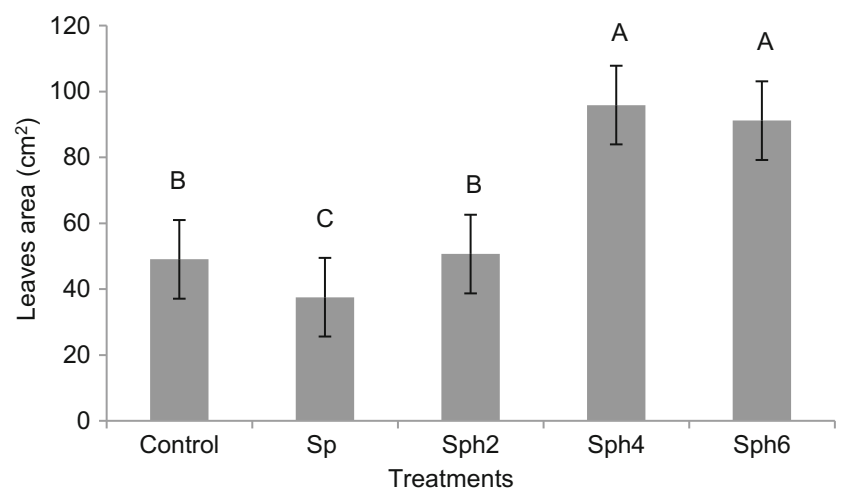

Fig. 2 Leaf area of lettuce seedlings treated with foliar applications of suspensions of lyophilized biomass of Arthrospira platensis (Sp), and the Sp biomass subjected to 2-h (Sph2), 4-h (Sph4), and 6-h (Sph6) hydrolysis, at a concentration of $2 \mathrm{~mL} \mathrm{~L}^{-1}$ and a control. At the same letter in the columns, the values did not differ by Tukey's test $(p<0.05)$. Bars represent standard error 


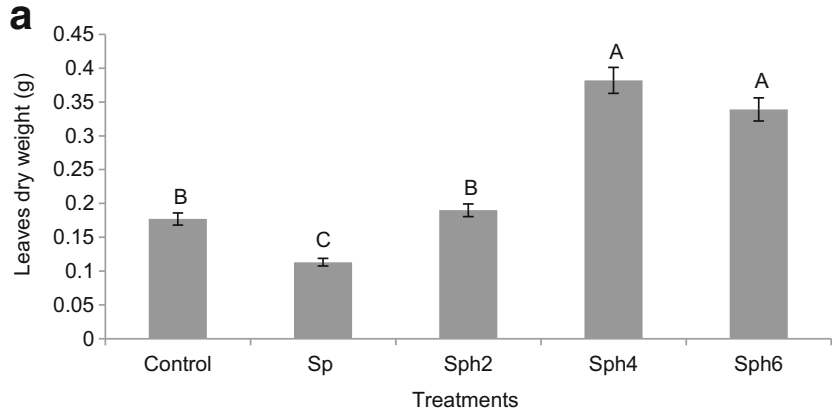

b
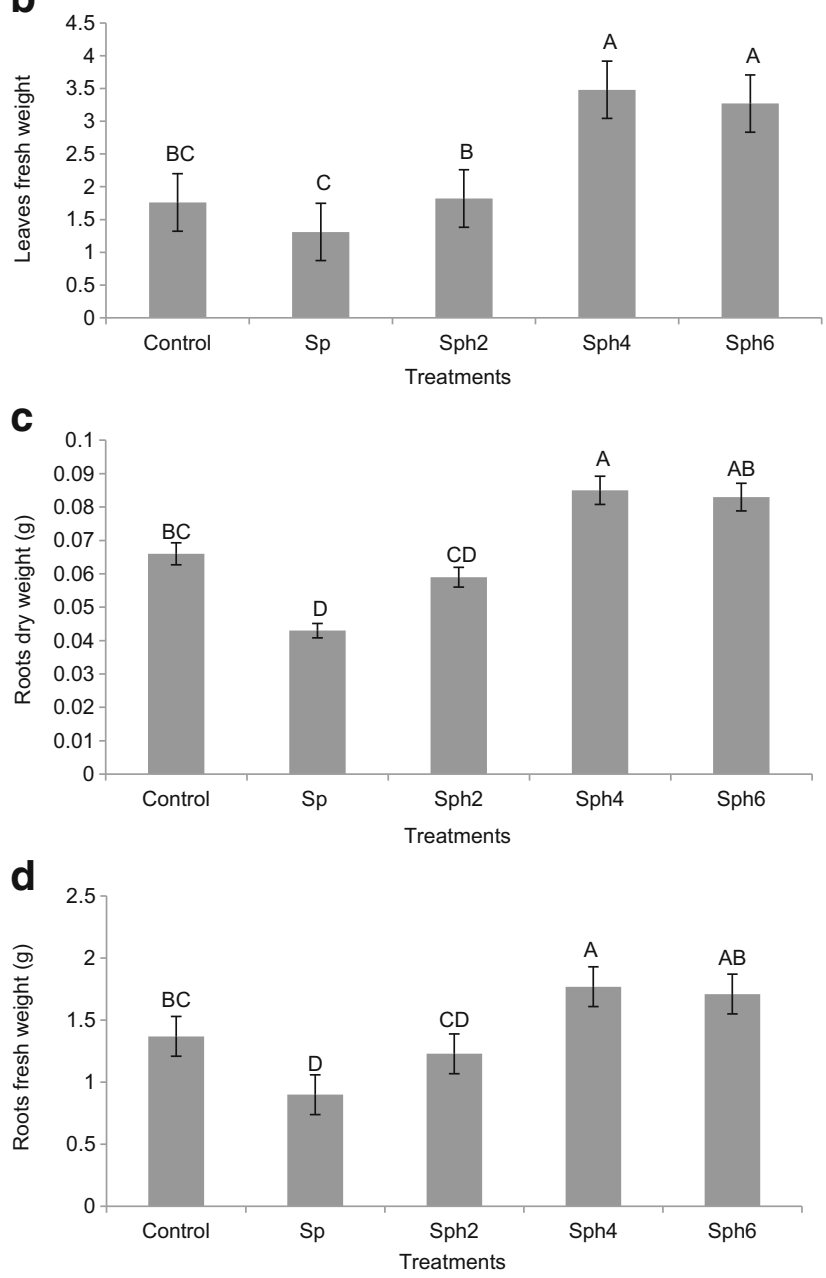

Fig. 3 Leaf dry weight (a), leaf fresh weight (b), root dry weight (c), and root fresh weight (d) of lettuce seedlings treated with foliar applications of suspensions of lyophilized biomass of Arthrospira platensis (Sp) at a concentration of $2 \mathrm{~g} \mathrm{~L}^{-1}$, and to biomass subjected to 2-h (Sph2), 4-h (Sph4), and 6-h (Sph6) hydrolysis, applied at a concentration of $2 \mathrm{~mL} \mathrm{~L}^{-1}$ and a control. At the same letter in the columns, the values did not differ by Tukey's test $(p<0.05)$. Bars represent standard error

of $1.060-1.777$ and $1.792-2.212 \mu \mathrm{g} \mathrm{g}^{-1}$, respectively. In contrast, the Spm content showed relevant differences. Compared to the control, the Spm concentration increased $63.94 \%$ in plants treated with Sph4 at $2 \mathrm{~mL} \mathrm{~L}^{-1}$ (Fig. 5). Therefore, it could be presumed that Sph4 triggered the biosynthesis of Spm in lettuce plants and is involved in hydrolysate bioactivity
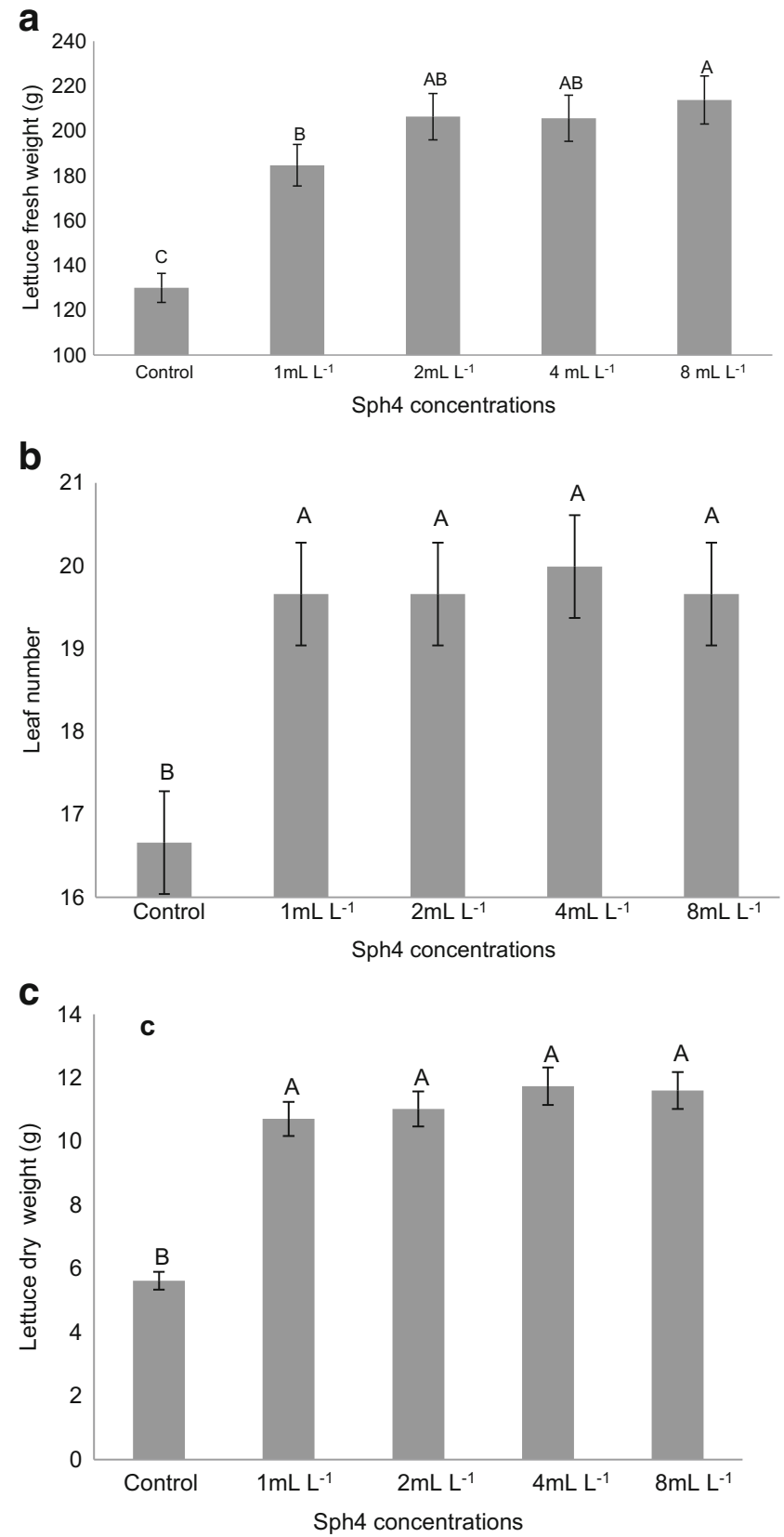

Fig. 4 Fresh weight (a), leaf number (b), and dry weight (c) of organically grown lettuce treated with foliar application of Arthrospira platensis biomass subjected to 4 -h hydrolysis (Sph4) at concentration of $1,2,4$, and $8 \mathrm{~mL} \mathrm{~L}^{-1}$ and a control. At the same letter in the columns, the values did not differ by Tukey's test $(p<0.01)$. Bars represent standard error

that promoted changes on plant ontogeny by improvement of leaf emission (Fig. 4b) and on plant growth by increments of biomass accumulation (Fig. 4a, c).

\section{Changes of free polyamines in A. platensis hydrolysate}

The hydrolysis of A. platensis biomass, a recognized protein source with values around $60 \%$, could release a range of 


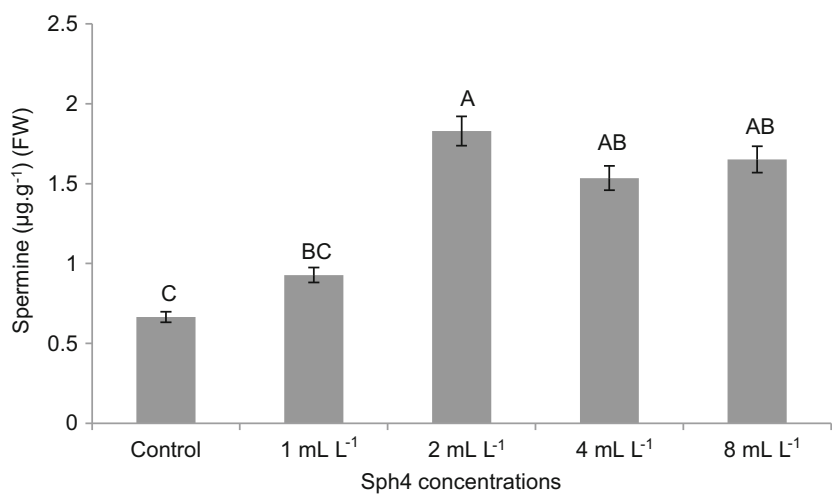

Fig. 5 The polyamine spermine content in lettuce leaves treated with foliar application of Arthrospira platensis biomass subjected to 4-h hydrolysis (Sph4) at concentration of 1,2, 4, and $8 \mathrm{~mL} \mathrm{~L}^{-1}$ and a control. At the same letter in the columns, the values did not differ by Tukey's test $(p<0.05)$. Bars represent standard error

bioactive compounds including PAs. The determination of free PA content in A. platensis biomass after 4-h hydrolysis reaction (Sph4) showed a $41 \%$ reduction in Put, a PA related to senescence and a 34\% increase in Spm, and a PA related to cell division, ontogeny, and growth, in comparison to nonhydrolyzed biomass (Fig. 6). These changes in reducing Put and improving Spm reinforce the probable role of Spm on field results with Sph4 applications.

\section{Discussion}

The first step of this study to investigate the growth-promoting properties of A. platensis hydrolysates verified that Sph4 and Sph6 were capable of increasing fresh weight of cucumber cotyledons in bioassays with activity higher than $0.3 \mathrm{mg} \mathrm{L}^{-1}$ KIN (Fig. 1b). These types of bioassays are well reported in studies investigating hormone-like activities in humic substances (Ron'zhina 2003; Scaglia et al. 2016) and algae (Stirk et al. 2002). Algal extracts can stimulate the hormone synthesis in plants and have a signaling action as a role in plant growth promotion (Wally et al. 2013). In addition, other bioactive compounds in algae extracts such as amino acids and polyamines can promote plant growth in a similar way to hormones (Kusano et al. 2008). Therefore, despite the use of KIN as a cytokinin source for comparison, the effect on cucumber cotyledons could have been triggered by various other bioactive compounds.

The use of seedling growth to evaluate the effects of seaweeds and microalgae has been reported previously (Hernández-Herrera et al. 2013; Garcia-Gonzalez and Sommerfeld 2016) and was used in this study as a part of a step-by-step approach (Povero et al. 2016). Improvement of lettuce seedling growth (Figs. 2 and 3) corroborated the bioassay results relating to the growth promotion to the hydrolysis with Sph4 and Sph6 being the most effective. These results

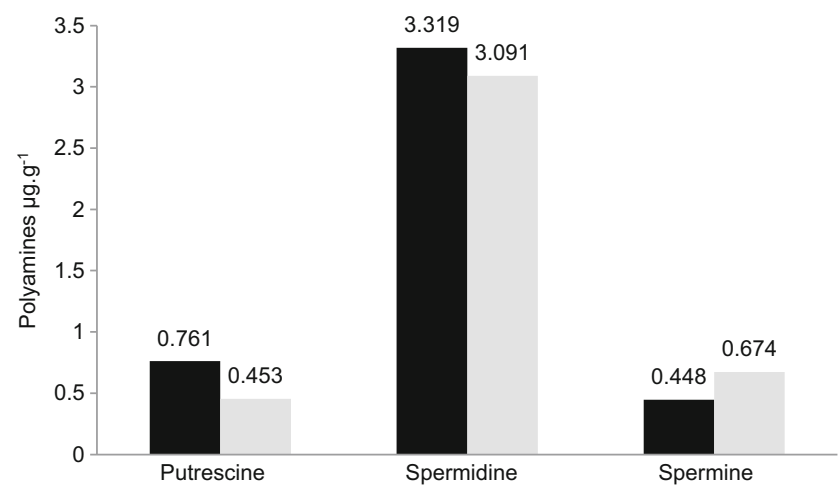

Fig. 6 Average values $(n=3)$ of free polyamines in lyophilized biomass of Arthrospira platensis (black column) and in biomass subjected to 4-h hydrolysis reaction (gray column)

highlighted the growth promotion property of the hydrolysates at early stages of lettuce plant development. Similar results were reported for lettuce seedling growth promotion using C. vulgaris biomass, but at lower rates than those found with Sph4 (Faheed and Abd-El Fattah 2008).

In the field trial with high-fertility soils that have been under organic cultivation for a long period, foliar applications of Sph4 confirmed bioassay and seedling results with Sph4 increasing fresh weight, leaf number, and dry weight in lettuce plants (Fig. 4). In order to elucidate the possible mechanisms of growth promotion of the hydrolysates even under adequate fertility conditions, The PA content was analyzed as these amines are present in all plant tissues and have similar effects as plant hormones, such as stimulating cell division and growth (Mattoo et al. 2010). PAs can modulate gene expression related to the action of CK and are thus capable of showing CK-like activity (Rakova and Romanov 2005), as found in the bioassays performed in the current study.

The free PA determination on field-grown lettuce leaves at harvest showed no differences for Put and Spd. However, Spm content increased by $64 \%$ in plants treated with Sph4 (Fig. 5). Polyamines have a role in plant development and act in secondary metabolic pathways. They accumulate in high concentrations in actively proliferating cells and are involved in a variety of fundamental cellular processes, including protein synthesis and modulation of enzyme activities, being effectors of plant growth (Takahashi and Kakehi 2010). Therefore, it is possible to assume that the CK-like effect of Sph4 found in the bioassays and their growth promotion effect on lettuce seedlings could be linked to PA metabolism. Sph4 contains $4.218 \mu \mathrm{g} \mathrm{g}^{-1}$ free PAs (Fig. 6) which is similar to that found in the macrolga Ecklonia maxima, a species widely used as a biostimulant (Papenfus et al. 2012).

The change on proportion of PAs after hydrolysis could also explain, at least in part, the Sph4 bioactivity, due to a 40\% reduction in Put and a 34\% increase in Spm compared to the non-hydrolyzed biomass. Put is a senescence induction factor (Xie et al. 2014) while Spm is an anti-senescence- 
inducing factor (Pandey et al. 2000) that increases metabolic activity and cell division (Kusano et al. 2008; Mattoo et al. 2010). Those referred roles of Spm on plant metabolism, and their increase in lettuce plants treated with Sph4, link this PA to the growth promotion effect of the hydrolysate.

The pathway of PAs is closely related to amino acid metabolism in plants with Put synthesized by decarboxylation of L-ornithine and L-arginine. Subsequently, the $P u t$ is converted into $S p d$ by the enzyme spermidine-synthase, which in turn is converted to Spm by spermine-synthase (Mehta et al. 2002). Thus, taking into account that $A$. platensis is a recognized protein source (Lisboa et al. 2016) and whose enzymatic hydrolysis of biomass can result in L-amino acids (Zhang and Zhang 2013), these probably are a part of the range of bioactive compounds in Sph4 related to plant growth and PAs.

This study on the hydrolyzed biomass of A. platensis revealed bioactivity in bioassays which corresponded to positive effects on lettuce seedling growth and in an organic field trial with lettuce. In addition, its effect on improvement of Spm concentrations in the leaves supports the conclusion that Sph4 is a natural plant growth promoter source for sustainable agriculture and its effect, at least in part, is related to PA metabolism in that Spm could be a metabolic indicator and also a bioactive compound. The role of Sph4 on triggering the increase of Spm content and promoting plant growth and the presence of other bioactive compounds of hydrolyzed A. platensis biomass, such L-amino acids, must be further investigated.

Acknowledgements The publication is supported by the EFOP-3.6.3VEKOP-16-2017-00008 project. The project is co-financed by the European Union and the European Social Fund. The authors highly appreciate the valuable contribution of Dr. Wendy Ann Stirk to the improvement of the manuscript and to Dr. Sergio O. Lourenço and Dra. Elisabete Barbarino for providing the cyanobacterium strain from Microalgae Collection "Elizabeth Aidar" at Fluminense Federal University, Niteroi, Rio de Janeiro-Brazil.

\section{References}

Aly MHA, Abd El-All Azza AM, Mostafa SS (2008) Enhancement of sugarbeet seed germination, plant growth, performance and biochemical compounds as contributed by algal extracellular products. J Agric Sci 33:8429-8448

Arioli T, Mattner SW, Winberg PC (2015) Applications of seaweed extracts in Australian agriculture: past, present and future. J Appl Phycol 27:2007-2015

Du Jardin P (2015) Plant biostimulants: definition, concept, main categories and regulation. Sci Hort 196:3-14

Faheed FA, Abd-El Fattah Z (2008) Effect of Chlorella vulgaris as biofertilizer on growth parameters and metabolic aspects of lettuce plant. J Agric Soc Sci 4:1813-2235

Flores HE, Galston AW (1982) Analysis of polyamines in higher plants by high performance liquid chromatography. Plant Physiol 69:701706
Garcia-Gonzalez J, Sommerfeld M (2016) Biofertilizer and biostimulant properties of the microalga Acutodesmus dimorphus. J Appl Phycol 28:1051-1061

Hernández-Herrera RM, Santacruz-Ruvalcaba F, Ruiz-López MA, Norrie J, Hernández-Carmona G (2013) Effect of liquid seaweed extracts on growth of tomato seedlings (Solanum lycopersicum L.) J Appl Phycol 26:619-628

Hosoya R, Hamana K, Isobe M, Yokota A (2005) Polyamine distribution profiles within cyanobacteria. Microbiol Cult Coll 21:3-8

Hussain A, Hasnain S (2011) Phytostimulation and biofertilization in wheat by cyanobacteria. J Ind Microbiol Biotechnol 38:85-92

Incharoensakdi A, Jantaro S, Raksajit W, Mäenpää P (2010) Polyamines in cyanobacteria: biosynthesis, transport and abiotic stress response. In: Méndez-Vilas A (ed) Current research, technology and education topics in applied microbiology and microbial biotechnology. Formatex, Spain, pp 23-32

Kim NH, Jung SH, Kim SH, Ahn HJ, Ong KB (2014) Purification of an iron-chelating peptide from Spirulina protein hydrolysates. J Korean Soc Appl Biol Chem 57:91-95

Kusano T, Berberich T, Tateda C, Takahashi Y (2008) Polyamines: essential factors for growth and survival. Planta 228:367-381

Lima GPP, Rocha AS, Takaki M, Ramos PRR, Ono EO (2008) Comparison of polyamine, phenol and flavonoid contents in plants grown under conventional and organic methods. Int J Food Sci Technol 43:1838-1843

Lisboa CR, Pereira AM, Costa JAV (2016) Biopeptides with antioxidant activity extracted from the biomass of Spirulina sp. LEB 18. Afr J Microbiol Res 10:79-86

Mattoo AK, Minocha SC, Minocha R, Handa AK (2010) Polyamines and cellular metabolism in plants: transgenic approaches reveal different responses to diamine putrescine versus higher polyamines spermidine and spermine. Amino Acids 38:405-413

Mehta RA, Cassol T, Li N, Ali N, Handa AK, Mattoo AK (2002) Engineered polyamine accumulation in tomato enhances phytonutrient content, juice quality, and vine life. Nat Biotechnol 20:613-618

Osman MEH, El-Sheekh MM, El-Naggar AH, Gheda SF (2010) Effect of two species of cyanobacteria as biofertilizers on some metabolic activities, growth, and yield of pea plant. Biol Fertil Soils 46:861875

Pandey S, Ranade SA, Nagar PK, Kumar N (2000) Role of polyamines and ethylene as modulators of plant senescence. J Biosci 25:291299

Papenfus HB, Stirk WA, Finnie JF, Van Staden J (2012) Seasonal variation in the polyamines of Ecklonia maxima. Bot Mar 55:539-543

Povero G, Mejia JF, Tommaso DD, Piaggesi A, Warrior P (2016) A systematic approach to discover and characterize natural plant biostimulants. Front Plant Sci. doi:10.3389/fpls.2016.00435

Rakova NY, Romanov GA (2005) Polyamines suppress manifestation of cytokinin primary effects. Russ J Plant Physiol 52:50-57

Reichert CC, Reinehr CO, JAV C (2006) Semicontinuous cultivation of the cyanobacterium Spirulina platensis in a closed photobioreactor. Braz J Chem Eng 23:23-28

Ron'zhina ES (2003) Cytokinin-regulated mesophyll cell division and expansion during development of Cucurbita pepo leaves. Russ $\mathrm{J}$ Plant Physiol 50:646-655

Scaglia B, Nunes RR, Rezende MO, Tambone F, Adani F (2016) Investigating organic molecules responsible of auxin-like activity of humic acid fraction extracted from vermicompost. Sci Total Environ 562:289-295

Singh JS, Kumar A, Rai AN, Singh DP (2016) Cyanobacteria: a precious bio-resource in agriculture, ecosystem, and environmental sustainability. Front Microbiol. doi:10.3389/fmicb.2016.00529

Srivastava AK, Rai AN, Neilan BA (2013) Stress biology of cyanobacteria: molecular mechanisms to cellular responses. CRC Press, Taylor and Francis Group 
Stadnik MJ, Freitas MB (2014) Algal polysaccharides as source of plant resistance inducers. Trop Plant Pathol 39:111-118

Stirk WA, Ördog V, Van Staden J, Jäger K (2002) Cytokinin- and auxinlike activity in cyanophyta and microalga. J Appl Phycol 14:215-221

Takahashi T, Kakehi JI (2010) Polyamines: ubiquitous polycations with unique roles in growth and stress responses. Ann Bot 105:1-6

Tripepi RR, George MW (1991) Identification of bacteria infecting seedlings of mung bean used in rooting bioassays. J Am Soc Hortic Sci 116:80-84

Vera-Sirera F, Minguet EG, Singh SK, Ljung K, Tuominen H, Blázquez MA, Carbonell J (2010) Role of polyamines in plant vascular development. Plant Physiol Biochem 48:534-539

Wally OSD, Critchley AT, Hiltz D, Craigie JS, Han X, Zaharia LI, Abrams SR, Prithiviraj B (2013) Regulation of phytohormone biosynthesis and accumulation in Arabidopsis following treatment with commercial extract from the marine macroalga Ascophyllum nodosum. J Plant Growth Regul 32:324-339
Wang X, Zhang X (2012) Optimal extraction and hydrolysis of Chlorella pyrenoidosa proteins. Bioresour Technol 126:307-313

Xie SS, Wu HJ, Zang HY, Wu LM, Zhu QQ, Gao XW (2014) Plant growth promotion by spermidine-producing Bacillus subtilis OKB105. Mol Plant-Microbe Interact 27:655-663

Yee NN, Aye SM, Htun TT (2012) Effect of spirulina on germination, growth, yield and nutritional value of wheat. Univ Res J 5:37-57

Zarrouk C (1966) Contribution a l'etude d'une cyanobacterie: influence de divers facteurs physiques et chimiques sur la croissance et la photosynthese de Spirulina maxima (Setchell et Gardner) Geitler. Thesis, University of Paris

Zhang B, Zhang X (2013) Separation and nanoencapsulation of antitumor polypeptide from Arthrospira platensis. Biotechnol Prog 29:1230 1238

Zhao ZR, Wu ZL, Huang GQ, Li GR (1992) An improved disk bioassay for determining activities of plant growth regulators. J Plant Growth Regul 11:209-213 